\title{
Available for You: The activist art of hospitality and friendship
}

\author{
Photo-essay by Gil \& Moti \\ Rotterdam, Netherlands \\ gilmoti@xs4all.nl
}

\begin{abstract}
The essay documents the action-installation Available for You, by the Israeli-Dutch artist duo Gil \& Moti, in which they offer their free services to Arab residents of various European cities as a gesture of reconciliation and friendship at an interpersonal level. The encounters with strangers were documented in diary entries, photos and videos and sketches, presented in this essay. A playful and light-hearted humour provides a means of activism via personalised gestures as well as a means of bringing the quotidian realm into art.
\end{abstract}

Keywords: reconciliation, activism, Israeli-Palestinian conflict, artistic and social engagement, sharing.

In the action-installation Available for You (2009), the Israeli-Dutch artist duo Gil \& Moti offer their free services to Arab residents of various European cities, as a gesture of reconciliation, atonement and friendship at a microcosmic level. Following a public announcement in the form of a flyer and an online call, in which the artists seek to move beyond the political deadlock in the Israeli-Palestinian conflict through an interpersonal level of communication and solidarity, Gil \& Moti met with several people who expressed interest in their offering of services. The services ranged from helping someone renovate their house, to setting up shop, to spending time with children or even scrubbing a toilet. The encounters were documented in diary entries, photos, and videos, some excerpts of which are presented in this photo essay. Available for You has been developed since 2008 as an open, accessible, and growing personal diary. It takes the form of public actions, installations, texts, drawings, video material, and photos, which together tell the story of a journey that has so far taken the duo to Copenhagen, Rotterdam, Amsterdam, Stockholm, and Paris. People, rather than cities, are the protagonists of the project. Given that immigration is a central contentious topic in every European metropolis, the project Available for You implicitly extends its relevance from the Israel-Palestine issue to the question of immigration, hostility, and hospitality, with reference to Europe. It is an exceptional project that 
brings the complexity of dealing with cultural diversity out into the open, without fuss, and even makes it suitable for the art world.

Available for You is an investigation that initially appears innocent and generous, but which raises the issue of the complexity of coexistence in an intelligent and stratified manner. It develops from the series of projects undertaken by Gil \& Moti since 2002, in which they, as Israelis, reach out to Palestinians specifically, and Arabs in general, seeking communication at an interpersonal level where political communication seems to have reached an impasse. At the same time, they raise themes from an artistic perspective that apply globally: themes such as sociability, integration, and exclusion. On the border of the public and private domain and of the art institution and the street, they have created their project as a fascinating vision of an artistic and humanitarian practice in a changing world beset by conflict.

Gil \& Moti are aware of the discussion that relates to artistic and social engagement. In which arena is the work relevant, and where does it intend to be? As soon as artists take a step outside the white cube, much of what they do is received with a certain suspicion. And yet, much of the innovative art in recent decades came into being far from the conventional gallery or museum halls. Artists working in the grey area between art and cultural activism have developed new forms of collaboration with the public and with communities.

The playful blurring of the dividing line between life and art and between private and public space is central to Gil \& Moti's work as it is in those contemporary artworks characterised by the term "relational aesthetics", a concept proposed by the French art theorist and curator Nicolas Bourriaud (2002). Art comes into being in public space in the framework of initiatives that involve the participation of people apart from the artists themselves. In the case of Gil \& Moti, this has far-reaching consequences. Not only does it include other people acting in what can be defined as the artists' works; conversely the artistic statement also becomes a permanent part of Gil \& Moti's own lives. Like French artist Sophie Calle, Gil \& Moti stage events for themselves and other people. But whereas Calle does not abandon her defined artistic position, Gil \& Moti's project does not leave them with this possibility.

The photographic portraits in Available for You, of Mohamed, Mahir, Bouchra, Linda, Hanna, and others, flanked by Gil \& Moti, are loaded with symbolism. The cheerfully smiling, identically dressed lads are the outsiders in the photo; while in everyday reality exactly the opposite is the case. The rather slapstick video in which Gil \& Moti spiritedly paint Bouchra's garden wall with a decoration she designed herself is comical and hilarious, and lightens up a loaded debate. Bouchra complains that she is frequently faced with unexpected personal questions regarding her religious beliefs. In their interaction with an Arab jeweler in the Netherlands, they share his worries about not yet having reached the level of proficiency required in order to qualify for Dutch citizenship.

Humour provides a means of activism via personalised gestures as well as a means of bringing the quotidian realm into art. To be available for someone from a culture marked as antagonised to one's own, also means to be willing to encounter a sense of humour not one's own. That is however no easy task, for the videos of Gil \& Moti mainly portray their own view as artists, and less how they are viewed by others, although their presence on numerous photographs implies that they intensely subject themselves to the gaze of others. There is thus a difference between encountering the humour of another, and finding humour in the encounter with the other. In some instances, this takes the form of amusement at mundane features of an intimate environment, into which they have been invited. In the video Nasser (2008-2009), the opening shot shows a plastic alarm clock in the shape of a mosque on a windowsill of a Copenhagen 
apartment, announcing the Islamic call to prayer as a wake-up tone. Are Gil \& Moti amused at this mixture of sacred and profane in the way that outsiders to a culture are fascinated by its mundane pop-cultural artefacts? And is it meant merely as a humorous statement, when Hanna dramatically asks Gil \& Moti "to go down on their knees and scrub that toilet, to demand forgiveness for all the horrible things that your people did to my people!" (Figure 10)? Perhaps its seriousness is only possible to be expressed when coated with a humorous touch. Hanna's demand is a reminder of the words commonly attributed to Hannah Arendt, "one cannot forgive without the power to punish". Hanna's custodial offering of both punishment and forgiveness to Gil \& Moti demonstrates that she in fact lacks any such real powers. The eerie silence that follows this proclamation by Hanna and a slow-motion shot of Gil \& Moti doing the task demanded, is a directorial tool used consciously by the artists, to allow the viewer to contemplate on the earnestness that accompanies the humour, be it from their own perspective, or that of Hanna. The conflict they seek to repair at an interpersonal level lays bare the conflict of humour in the video, the undecidability as to who has the laugh and who is the object of the laugh.

The activist gesture in Available for You stems from Gil \& Moti's counterintuitive take on the conflict their biographies and those of their chosen partners are inscribed into. Rather than address ideologies, opinions or political affiliations, they enter with their bodies into the daily lives and intimate spaces of those who ask for their services, such that seemingly innocuous pedestrian tasks and conversations take the place of grand narrative and heroism. These encounters do not just provide the raw material for an artistic representation in an art gallery; rather they are themselves the work of art. Gil \& Moti's act of dressing identically, sharing everything in their lives, from a bank account to an email address, is not an artistic gimmick that lasts for a few hours, but a project for life. Its humour lies in the profound commitment to the seriousness of such an enterprise, the laughable courage to believe that two or more can become one.

In another video conversation, Nasser, the Lebanese grocer, tells Gil \& Moti:

...I have to get somebody to look after the shop. I haven't had a holiday for the last two years, working every day. [...] We can disagree about a lot of things, you believe in some things, I believe in other things. But we have to live together. We have to get along. Not only foreigners or Danish people, I'm talking about people all over the world.

(Gil \& Moti, Nasser, 2008-2009, video, 7’08”.)

The power of Available for You lies in the everyday, in the smallness of scale. Large (macro) political and social issues are addressed on a personal (micro) level, or rather, the interpersonal micro-level offers a perspective that playfully points to the rigidity that often impedes changes at the structural, macro-level. By means of simple actions, on the basis of tolerance and openness far away from Israel and Palestine, the relationship between Arabs and Jews acquires another meaning. And by actually placing personal experiences above collective assumptions, Available for You poses the question of what it means to form a community, who is included, and which opinions play a central role in it.

\section{References}

Bourriaud, N. (2002). Relational Aesthetics. Translated by S. Pleasance and F. Woods. Paris: Les presses du réel. 
Gil \& Moti (2009). Available for You. Copenhagen: Kunsthallen Nikolaj and Rotterdam: TENT. Gil \& Moti (2012). Totally Devoted to You. Berlin: Hatje Cantz.

\section{Available for You}

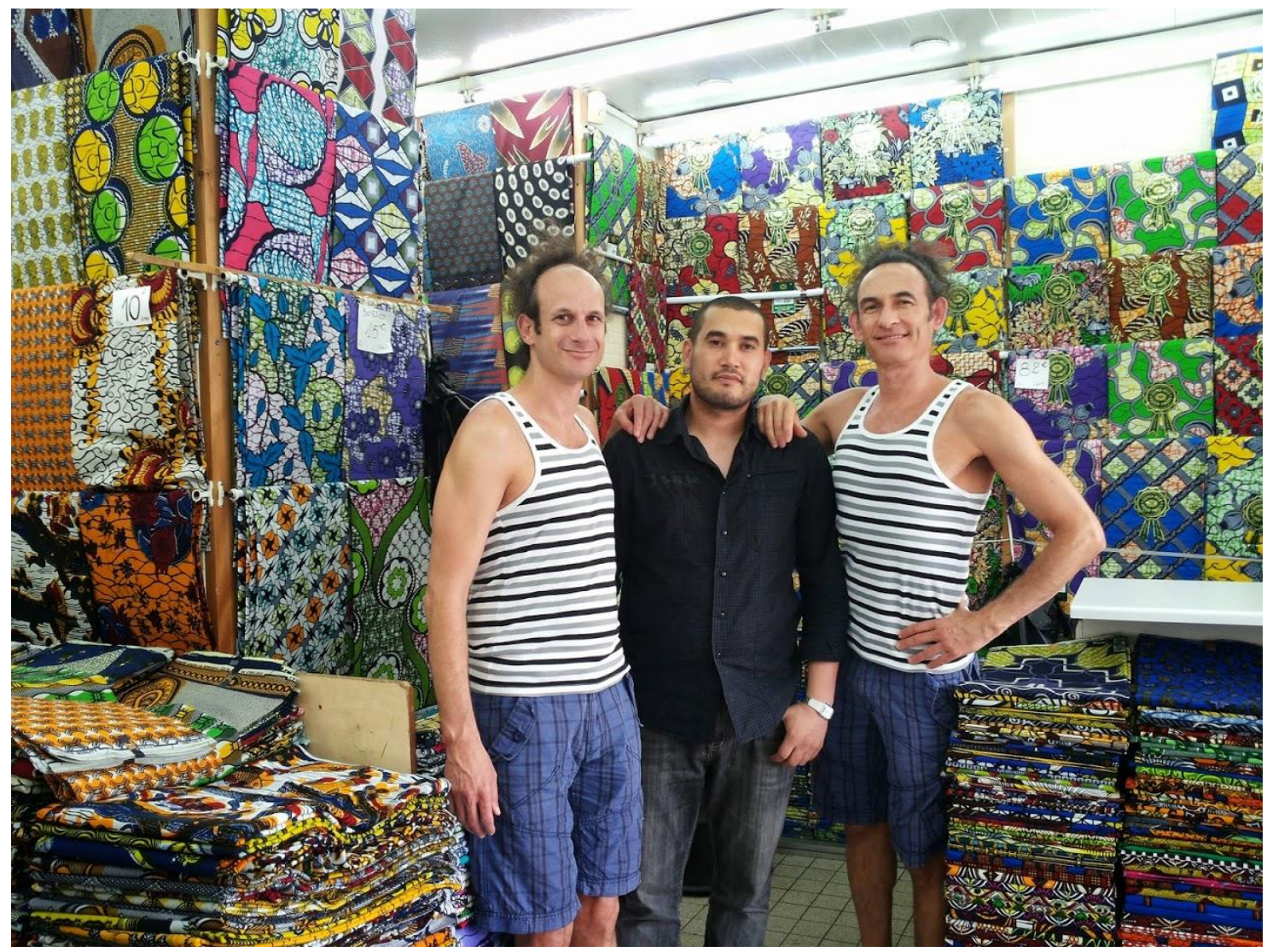

Figure 1. Gil \& Moti \& Aziz, 2013, c-print, 120x160 cm. 


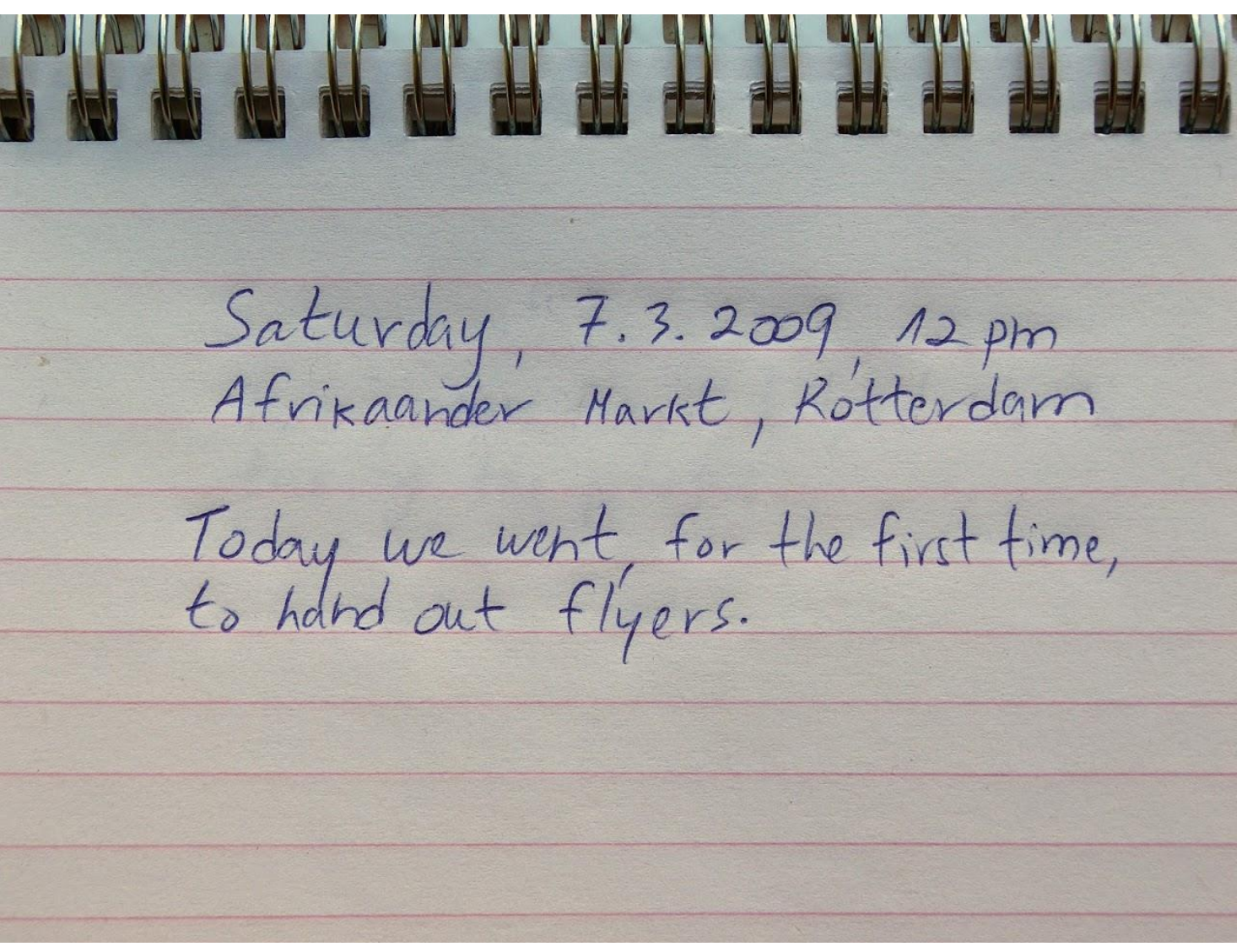

Figure 2. Gil \& Moti, Rotterdam Diary, 2009, video, 7'36". 


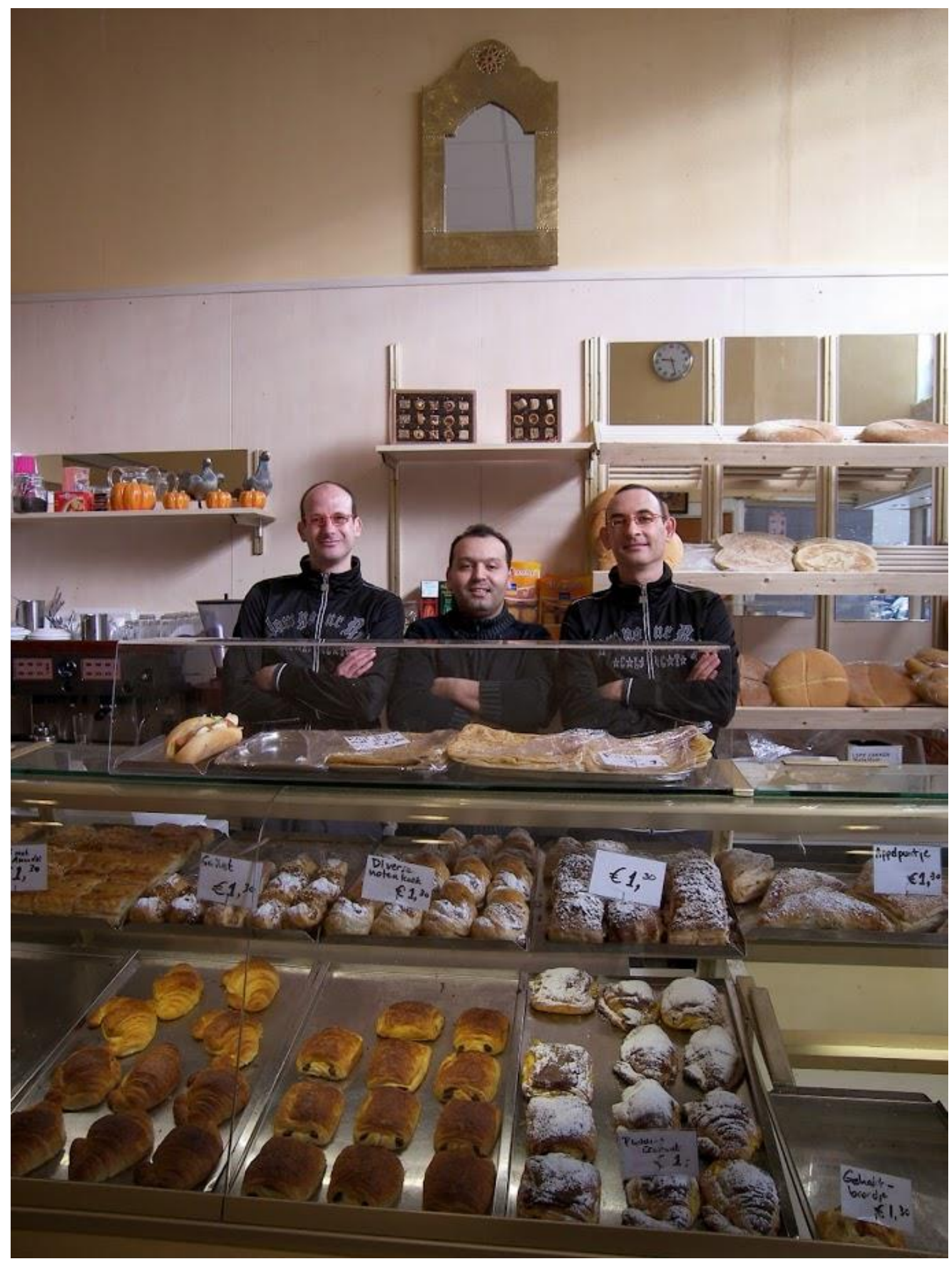

Figure 3. Gil \& Moti \& Joussef, 2008, c-print, 160x120 cm. 


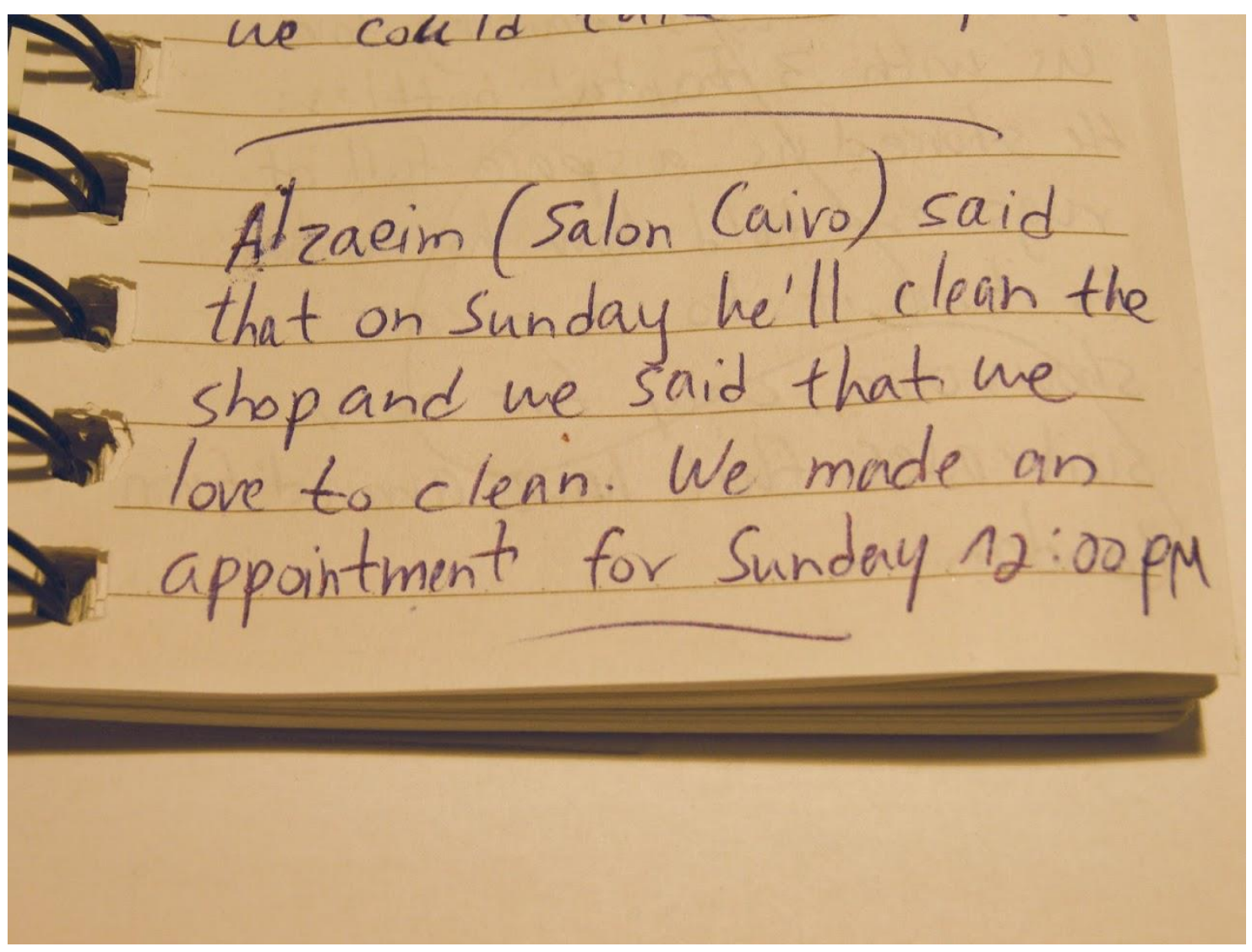

Figure 4. Gil \& Moti, Alzaeim, 2008, video, 4'38". 


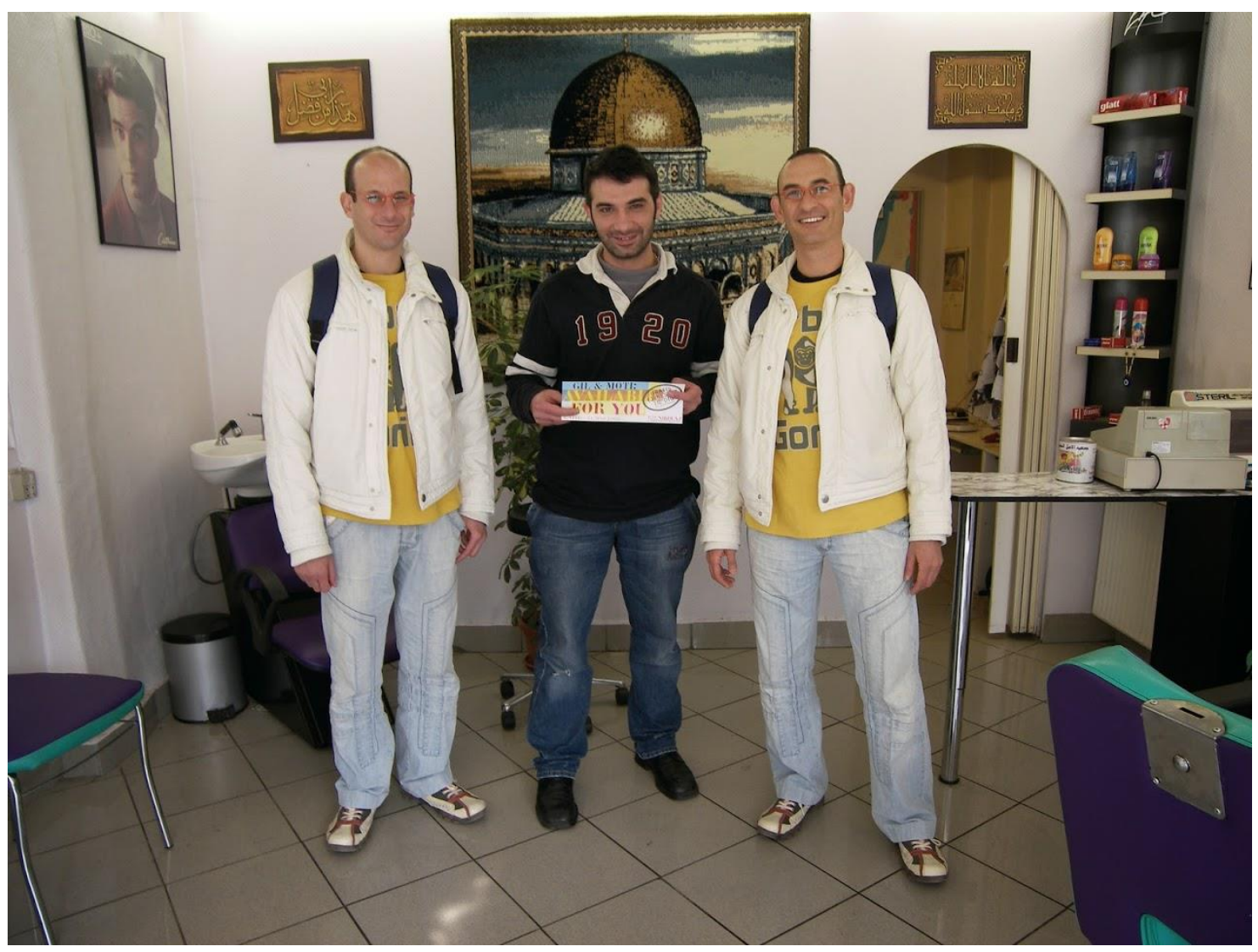

Figure 5. Gil \& Moti \& Alzaeim, 2008, c-print, 120x160 cm. 


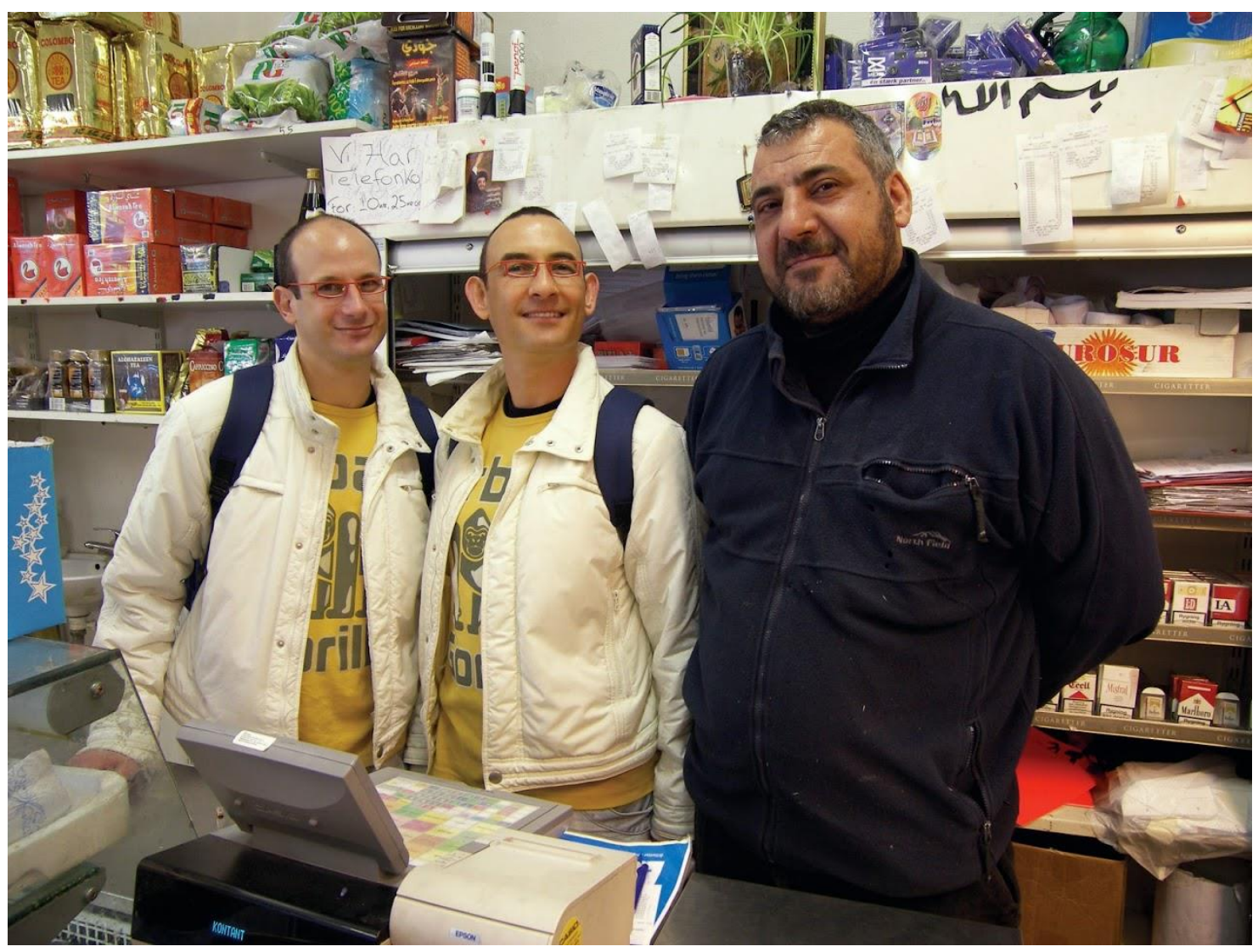

Figure 6. Gil \& Moti \& Nasser, 2008, c-print, 120x160 cm. 


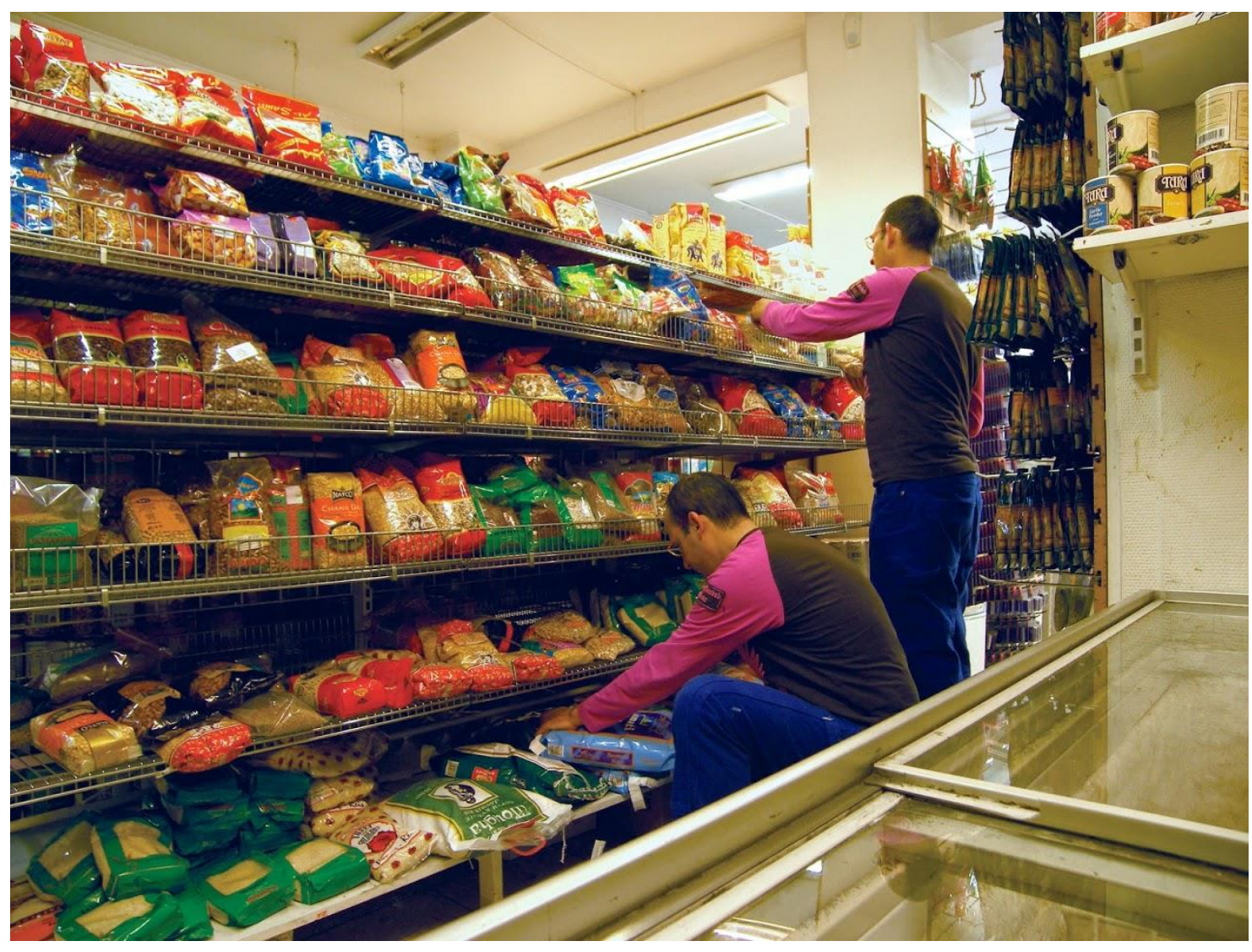

Figure 7. Gil \& Moti, Nasser, 2008-2009, video, 7'08". 


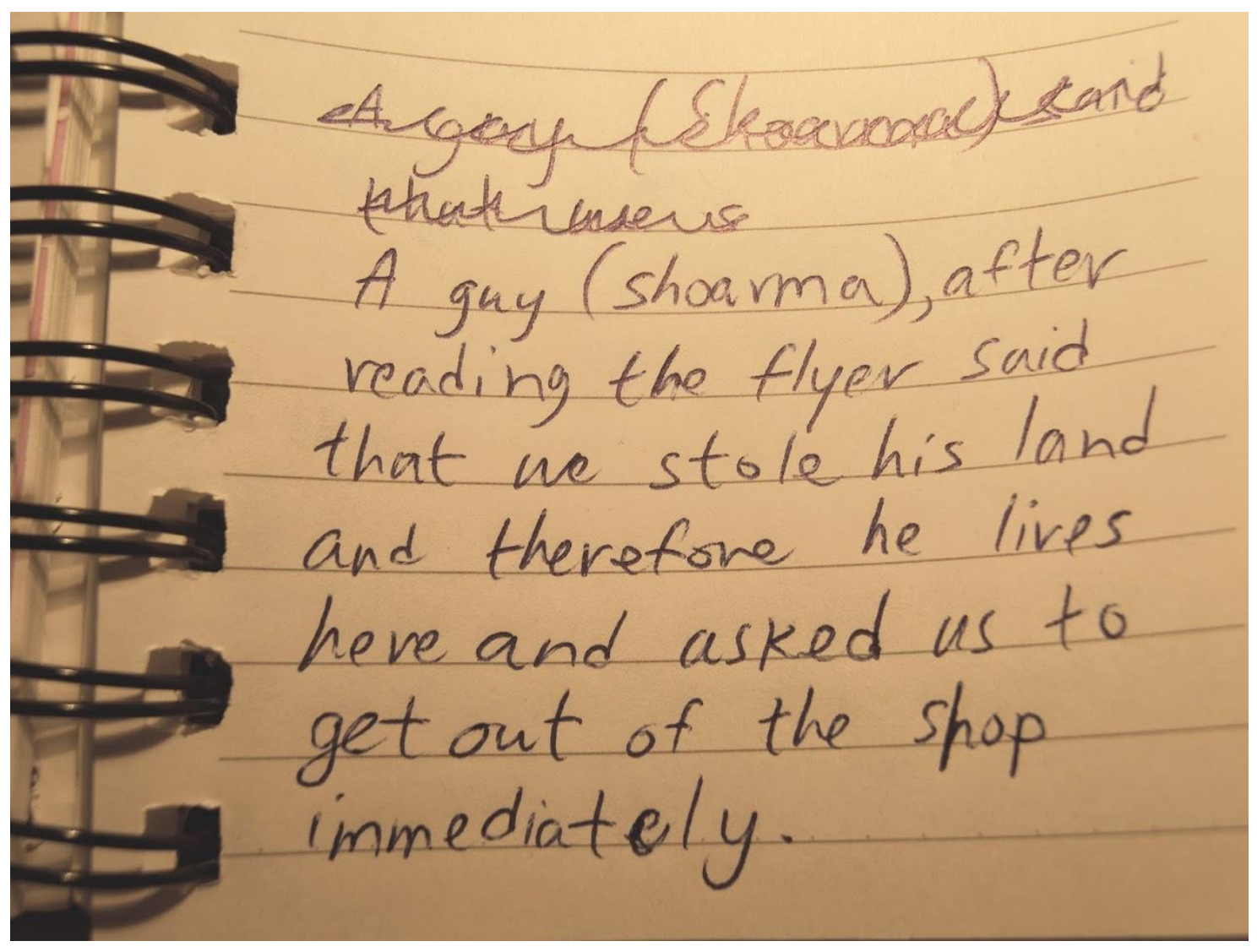

Figure 8. Gil \& Moti, Copenhagen Diary, 2008, video, 4'38". 


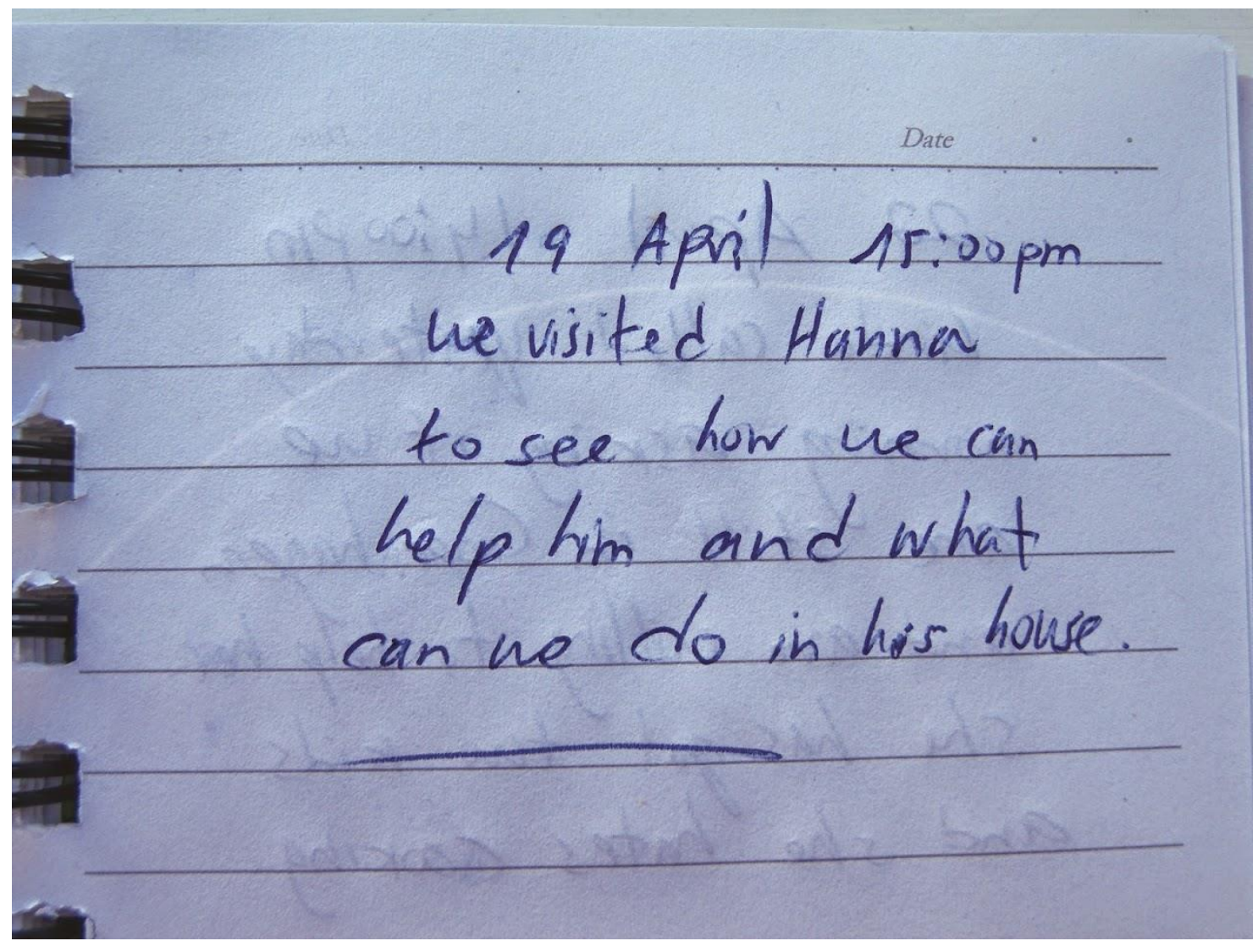

Figure 9. Gil \& Moti, Hanna, 2008-2009, video, 7'38". 


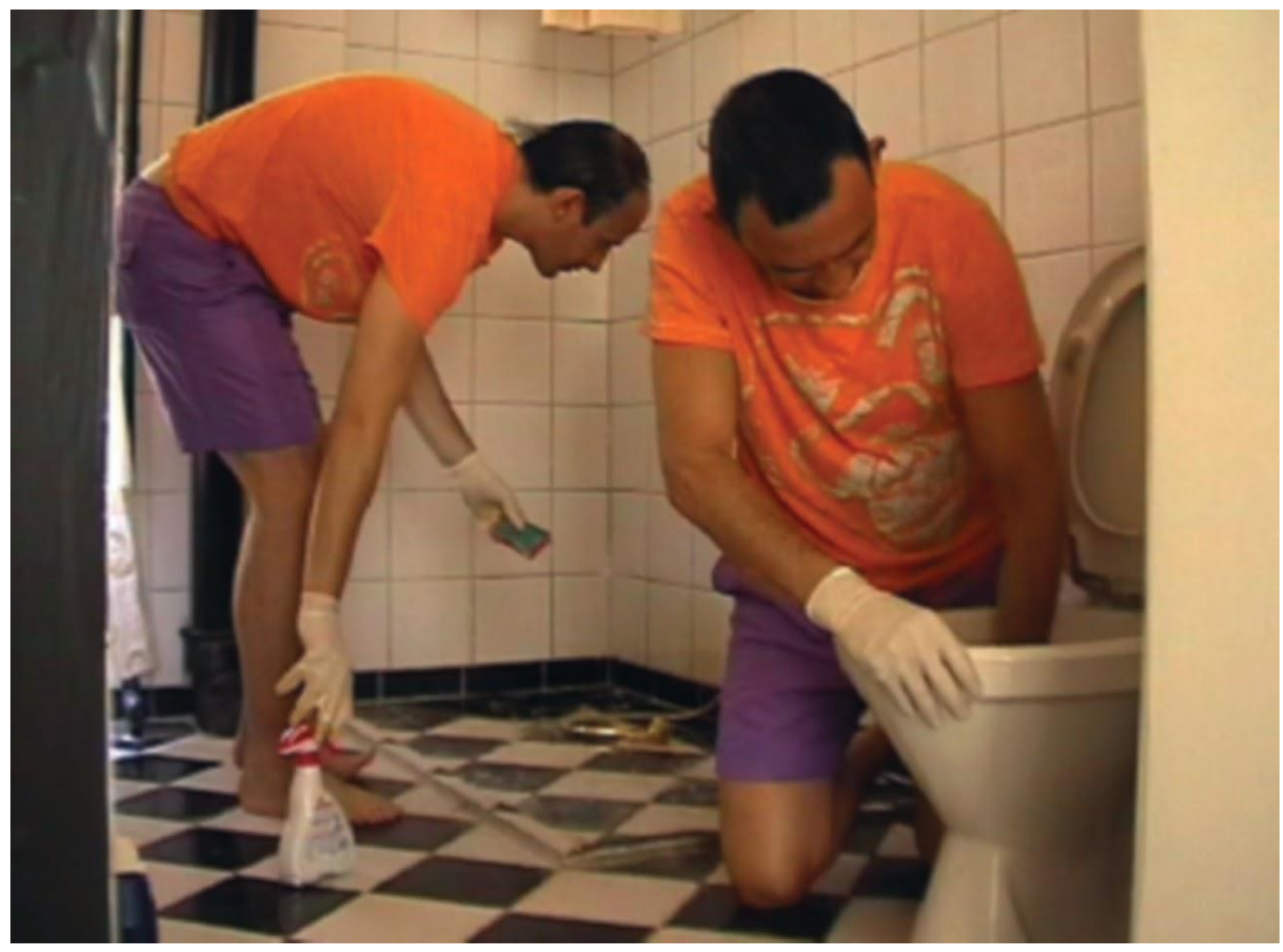

Figure 10. Gil \& Moti, Hanna, 2008-2009, video, 7'38". 


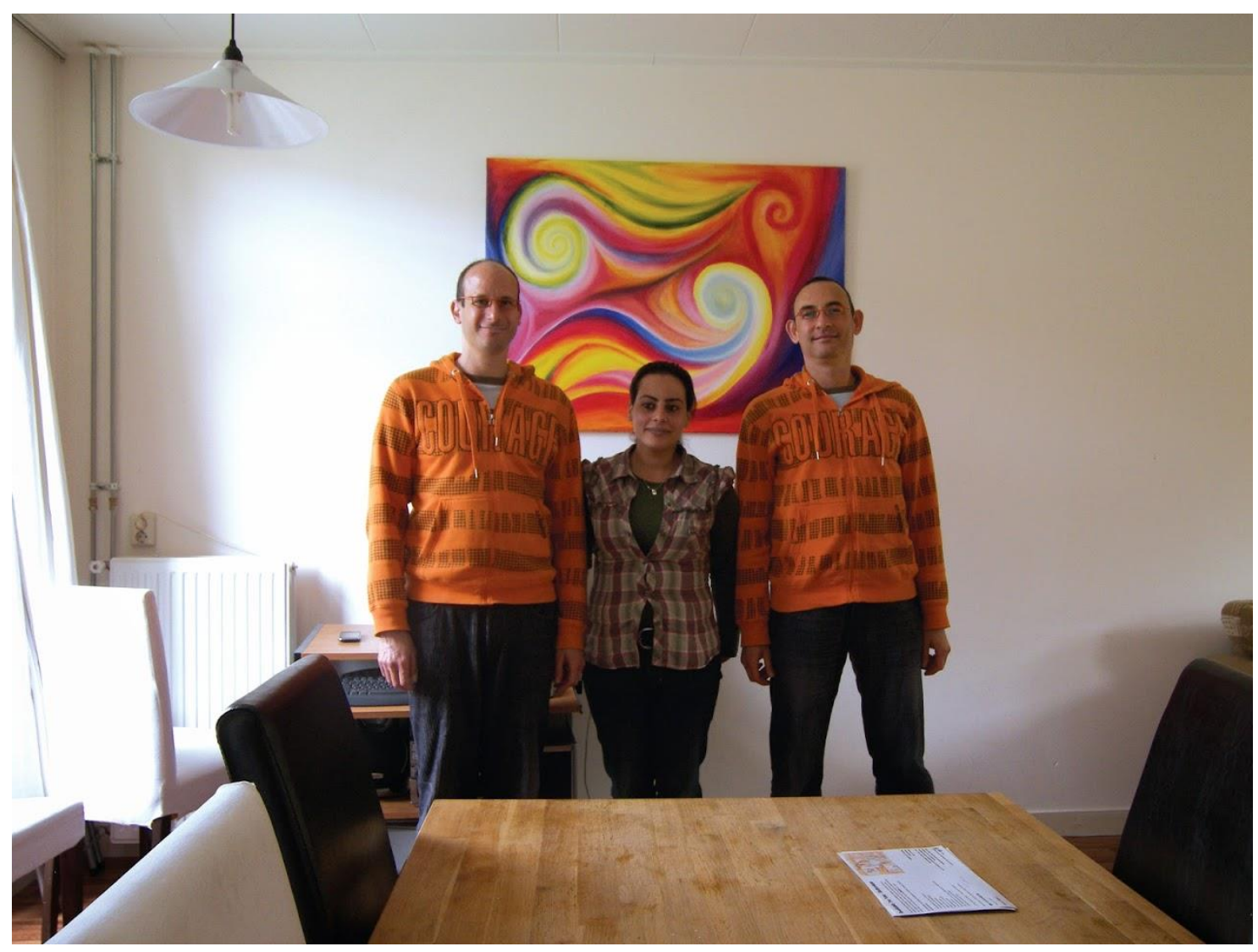

Figure 11. Gil \& Moti \& Bouchra, 2009, c-print, 120x160 cm. 


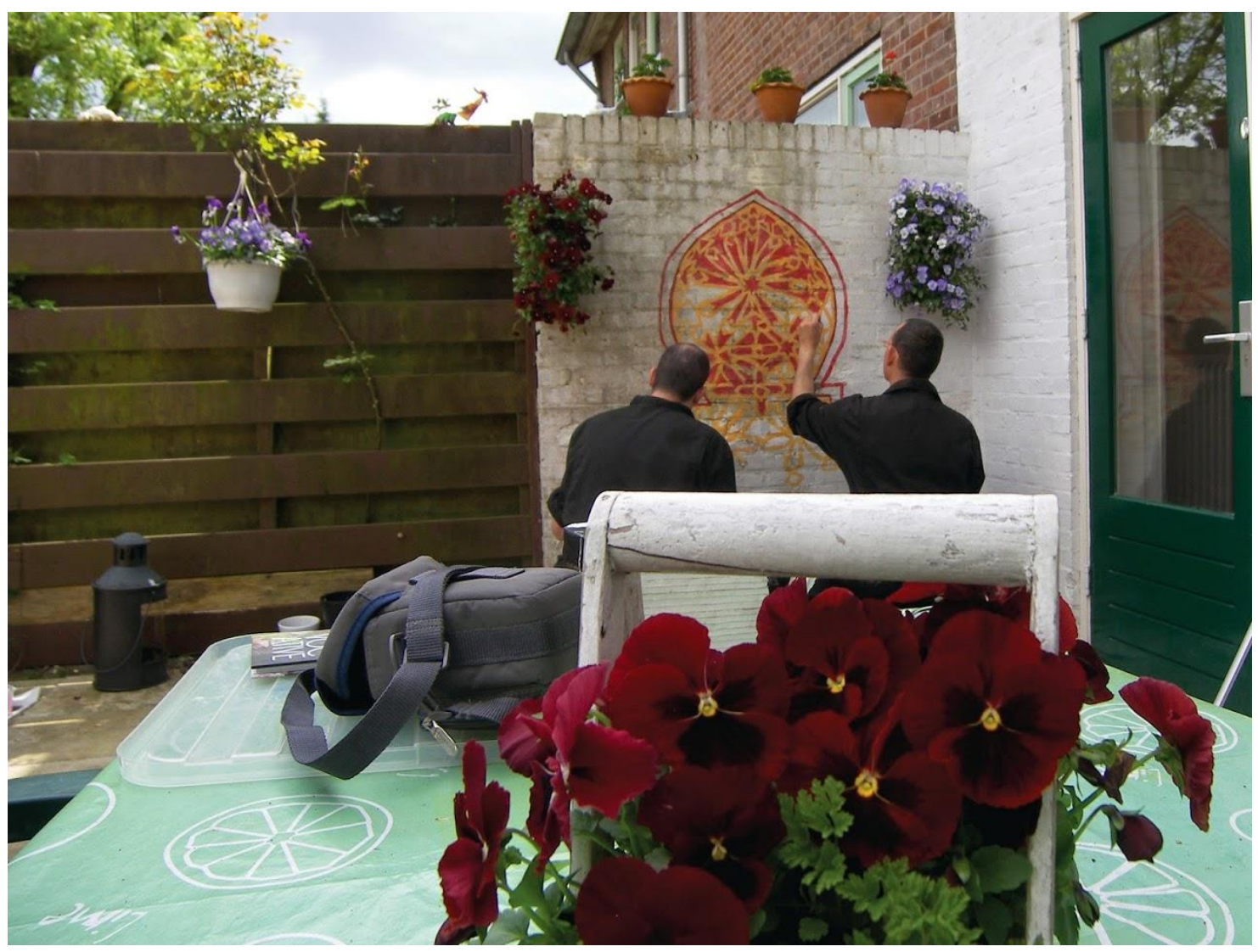

Figure 12. Gil \& Moti, Bouchra, 2009, video, 4'47". 


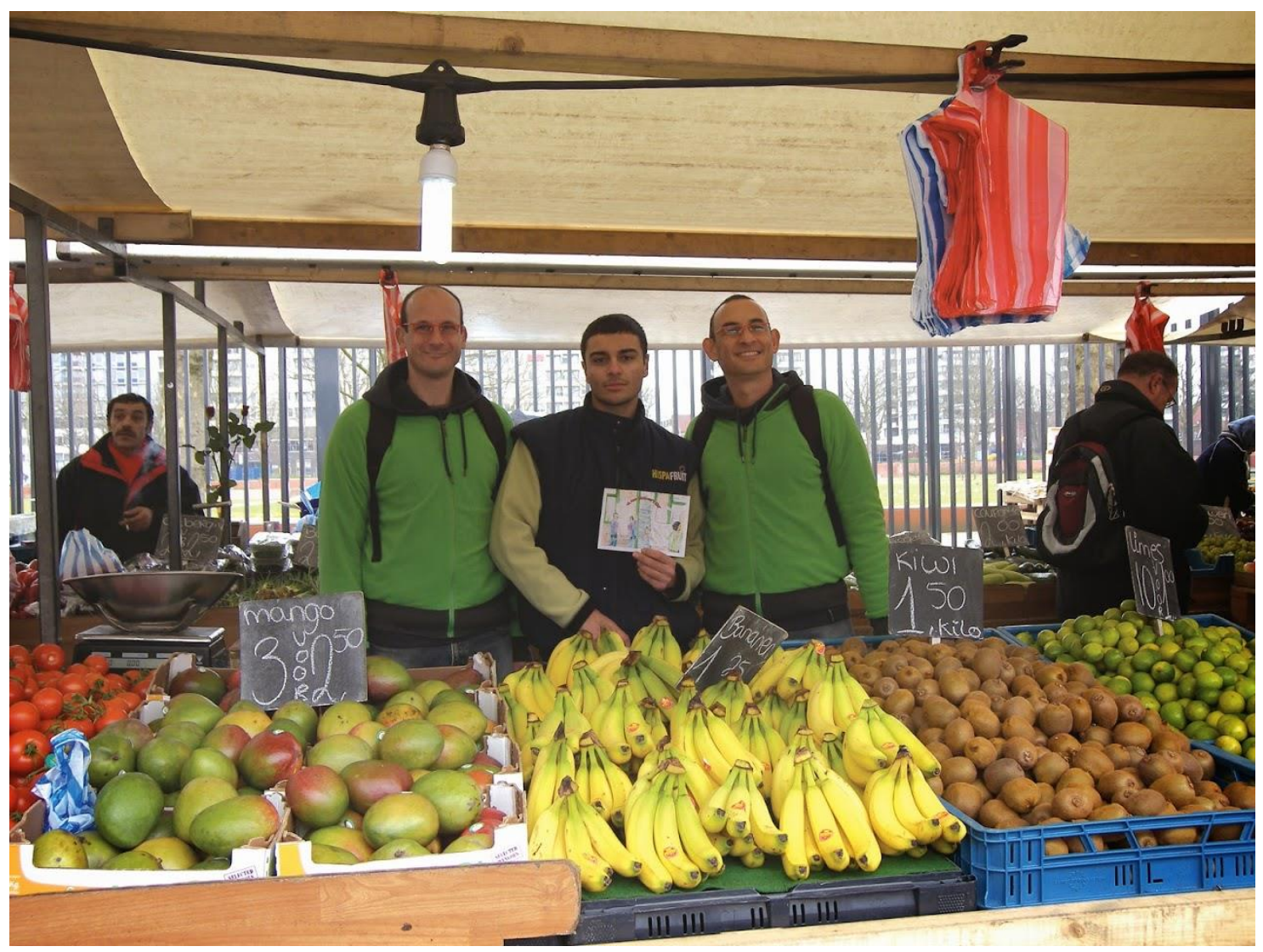

Figure 13. Gil \& Moti \& Hakim, 2009, c-print, 120x160 cm. 


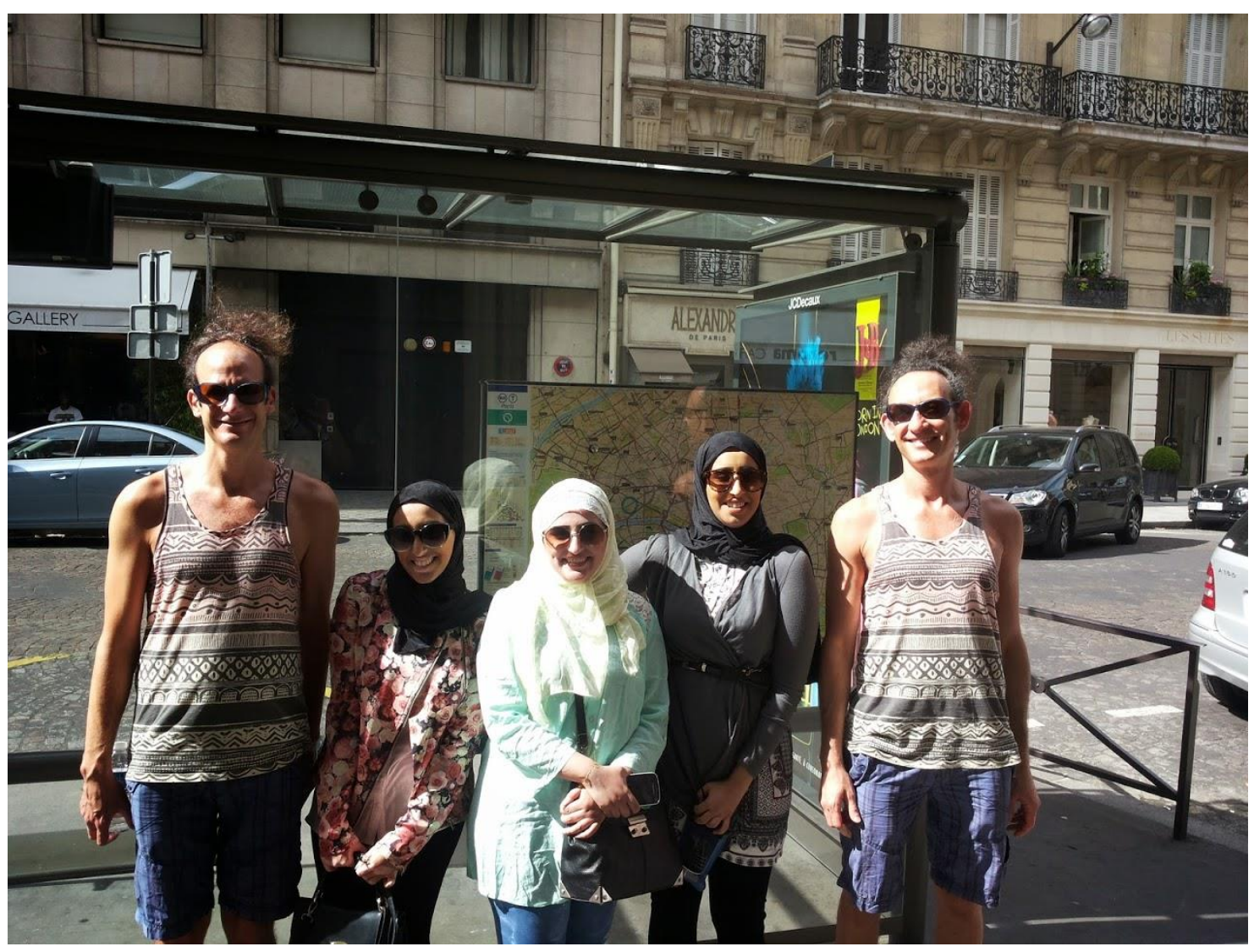

Figure 14. Gil \& Moti, Paris Diary, 2013, video, 5’36". 